\title{
ASSESSMENT OF CONTAMINATION POTENTIAL OF GROUNDWATER ADJACENT TO THE WASTE DISPOSAL SITE AT KHULNA: CONTAMINATION INDICES, MULTIVARIATE STATISTICS AND GEOSTATISTICAL APPROACH
}

\author{
Islam M. Rafizul* and Debatosh Banik Partha
}

Department of Civil Engineering, Khulna University of Engineering \& Technology, Khulna-9203, Bangladesh

Received: 01 July 2019

Accepted: 27 October 2020

\begin{abstract}
This study aimed to evaluate the contamination potential of groundwater using various contamination indices available in the literature. To these attempts, fifteen groundwater samples were collected during rainy and dry seasons from the selected tubewells located nearby waste disposal site at Rajbandh, Khulna, Bangladesh. In the laboratory, the concentration of metal elements such as $\mathrm{Fe}, \mathrm{Mn}, \mathrm{Cr}, \mathrm{Cu}, \mathrm{Pb}, \mathrm{Zn}, \mathrm{Ni}, \mathrm{Cd}, \mathrm{Na}, \mathrm{K}, \mathrm{Ca}$, As and $\mathrm{Mg}$ in groundwater were measured through stanadard methods. The contamination indices such as groundwater quality index (GWQI), degree of contamination $\left(C_{d}\right)$, heavy metal evaluation index (HEI) and heavy metal contamination index (HPI) were used to quantify the level of contamination of groundwater. The values of GWQI, $C_{d}, H E I$ and HPI of groundwater were found less in rainy season than that of dry season due to dilution of groundwater. GWQI reveals that $26.67 \%$ of tubewells yield very poor, while, $73.33 \%$ of poor water condition. The result of principal component analysis (PCA) indicates that As contamination in groundwater caused from anthropogenic activities, while, Na, Ca and Mg from natural sources. Pearson's correlations indicates that most of the metal elements were in highly positive correlations with each other. The spatial distribution of various indices reveals that contamination of groundwater was found comparatively higher in the nearest tubewells and decreases in relation to the increasing of water sampling distances. The outcome of this study will further be helpful for other researchers to quantify the level of contamination of groundwater from tubewells.
\end{abstract}

Keywords: Disposal site; Groundwater; Metal element; Contamination indices; Geostatistical analysis; PCA; Pearson's correlation.

\section{INTRODUCTION}

Waste disposal site or landfill is widely used for municipal solid waste (MSW) management practices all over the world (Adipah and Kwame, 2019; Mangimbulude et al., 2009). MSW disposal site is a method for disposing of refusal on land by utilizing the principles of engineering. Leachate, a toxic liquid generated from disposal site contains large amounts of organic and inorganic contaminants by means of physical, chemical and microbiological changes of deposited MSW in landfills. Leachate will continuously migrate through the soil strata and eventually the groundwater system that have been contaminated with metal elements such as lead $(\mathrm{Pb})$, copper $(\mathrm{Cu})$, zinc $(\mathrm{Zn})$, iron $(\mathrm{Fe})$, manganese $(\mathrm{Mn})$, chromium $(\mathrm{Cr})$, cadmium $(\mathrm{Cd})$, etc. and these metal elements lead to serious problems because they cannot be bio-degraded in soil (Kanmani and Gandhimathi, 2012). Continuous leachate formation at disposal site is considered as a serious environmental issue as it contains various type of contaminants like organic matter, inorganic pollutants, metal elements, trace elements (Nirmala and Jagath, 2013). Due to leachate formation, gradual metal element deposition in groundwater is considered as a hazardous environmental contamination as groundwater is directly consumed by human community through various kind of production well/tubewells. Therefore, contaminated groundwater causes various kind of fatal diseases in human body e.g. arsenic consumption through water causes skin cancer, bladder and lung cancer etc. (Pangkaj and Rafizul, 2019; Sinha and Prasad, 2019). Regular and long-term consumption of groundwater pollutants like $\mathrm{Pb}, \mathrm{Cd}$, As etc. finally end up generating cardiovascular diseases and diabetes. Contaminated groundwater simultaneously effects the bio-diversity of trees and animals. Uplifted groundwater if contaminated and consumed by animals, it can cause anaemia, emaciation, anorexia, weakness in animal body (Shen et al., 2018). The productivity and life span of trees are reduced due to metal element contamination in groundwater.

Khulna, the third largest city of Bangladesh is located at the south-western part of Bangladesh. It has an increasing growth rate of 5\% having total population of 2.3 million in Khulna zilla (BBS, 2011). In addition, water is the basic and one of the vital physical components to run the livelihood. But safe and adequate sustainable drinking water is all that the mankind need (Shah et al., 2014). With an increasing rate of this population, demand of drinking water also increases. River, pond, rain, and groundwater are the main source of water. Nevertheless, in coastal region like Khulna, salinity of water induced many problems. Rivers in Khulna region are established as 
polluted. It also includes metal element contamination (Kibria et al., 2016). Groundwater is a valuable renewable resource and usually microbiologically safe and chemically stable in the absence of direct contamination (WHO, 2011). The quality of groundwater primarily depends on geological formation of a particular region as well as anthropogenic or human activities. The rate of pollutant deposition in groundwater depends on seasons and precipitation throughout a year. Seasons can be sub-divided into two parts for most of the country: dry and rainy season. The presence/absence of rainwater infiltrated in groundwater have a direct influence on deposition of metal ion underneath of soil. General scenario depicts that, concentration of metal pollutants remains high in dry season in compare to rainy season due to concentrated point deposition of ions as well as lack of dilution facility to spread over an area. Rainy season facilitates rapid and spatial distribution of metal ions over an area which is not possible in dry season.

To investigate the level of contamination of groundwater, the contamination indices available in the literature were considered. In this study, fifteen water samples were collected from tubewells located nearby waste disposal site at Rajbandh, Khulna, Bangladesh. In the laboratory, concentrations of relevant metal elements of $\mathrm{Fe}, \mathrm{Mn}, \mathrm{Cr}$, $\mathrm{Cu}, \mathrm{Pb}, \mathrm{Zn}, \mathrm{Ni}, \mathrm{Cd}, \mathrm{Na}, \mathrm{K}, \mathrm{Ca}, \mathrm{As}$ and $\mathrm{Mg}$ in groundwater samples were measured through standard test methods. In addition, the contamination indices such as groundwater quality index (GWQI), degree of contamination $\left(C_{d}\right)$, heavy metal evaluation index (HEI) and heavy metal contamination index (HPI) were used to quantify the level of contamination. The maximum limit for GWQI of 100, for $\mathrm{C}_{\mathrm{d}}$ it is 3 (Al-Nakib et al., 1987), for HEI it is 20 (Edet and Offiong, 2002) and for HPI the limit is 100 (Prasad and Bose, 2001) were considered. The findings of the research will may help to other researchers to understand the variation of contamination potential of groundwater in dry and rainy season as well as to take proper decisions about choosing degree of contamination mitigation in a separate approach for dry and rain season.

\section{RESEARCH METHODOLOGY}

The overall methodology for sampling of groundwater from selected tubewells, laboratory investigations and analysis of various indices such as GWQI, $\mathrm{C}_{\mathrm{d}}$, HEI and HPI are discussed in the following articles.

\subsection{Study Area}

Khulna is the south-western sea-adjacent third largest city in the geography of Bangladesh and it's situated on the banks of Rupsha and Bhairab river. It's located at $22^{\circ} 49^{\prime} 0^{\prime \prime} \mathrm{N}$ and $89^{\circ} 33^{\prime} 0^{\prime \prime} \mathrm{E}$ with a total area of $4394.46 \mathrm{~km}^{2}$. The selected waste disposal site at Rajbandh shown in Figure 1, is a place at a distance about $7 \mathrm{~km}$ north from Khulna city centre. This is currently used as open dumping site and it causes contamination of surrounding surface water bodies, groundwater sources and underlying soil layer. Groundwater is the main source in Khulna division for drinking purpose and the toxicity control in such area is a mandatory work. To fulfil the desire objectives of this study, groundwater $(\mathrm{GW})$ samples were collected from fifteen tubewells located nearby waste disposal site (Figure 1).

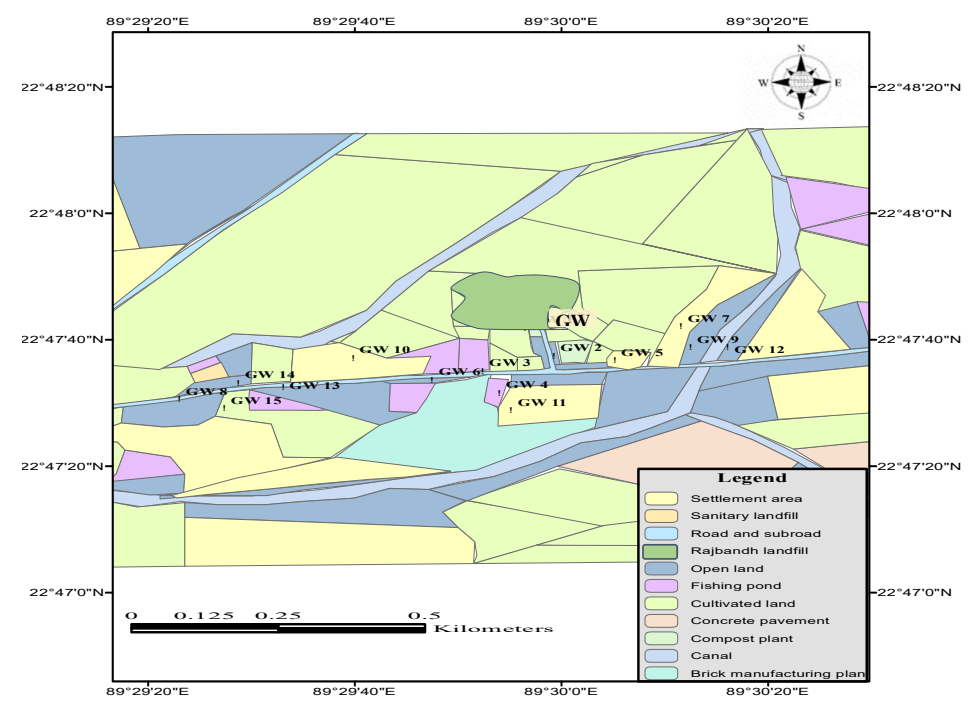

Figure 1: Map showing groundwater (GW) sampling locations from selected tubewells nearby waste disposal site 


\subsection{Collection of Groundwater}

Before collecting groundwater samples, the bottles were washed by distilled water several times. Then the bottles were air or sun dried. Then 2-3 mL a solution was used as preservative. The preservative was prepared by mixing concentrated nitric acid and distilled water at a ratio of 1:1. Then the bottle was kept for 24 hours at room temperature. After that the bottles were prepared for collecting water sample. In this study, fifteen groundwater samples were collected from selected tubewells located adjacent to the waste disposal site at Rajbandh of Khulna, Bangladesh. All sampling points were gathered with the help of GPS (Figure 1). These study periods covered both the rainy season (June to July 2017) and dry (October to November 2017) season. During both seasons, the groundwater samples were collected from same selected tubewells.

\subsection{Laboratory Investigations}

The groundwater samples were collected in a $500 \mathrm{~mL}$ HDPE bottle from the tubewells located nearby the waste disposal site and then brought to the laboratory. In the laboratory, the concentrations of metal elements of Fe, $\mathrm{Mn}$, $\mathrm{Cr}, \mathrm{Cu}, \mathrm{Pb}, \mathrm{Zn}, \mathrm{Ni}, \mathrm{Cd}, \mathrm{Na}, \mathrm{K}, \mathrm{Ca}, \mathrm{As}$ and $\mathrm{Mg}$ in groundwater samples were measured in $\mathrm{mg} / \mathrm{L}$ through Atomic Absorption Spectrophotometer (AAS).

\subsection{Groundwater Evaluation Indices}

To evaluate the level of contamination of groundwater, various indices such as groundwater quality index (GWQI), degree of contamination $\left(\mathrm{C}_{\mathrm{d}}\right)$, heavy metal evaluation index (HEI) and heavy metal contamination index (HPI) proposed by different researchers in the literature were used and hence discussed in the following articles.

\subsubsection{Groundwater Quality Index}

Groundwater quality index (GWQI) helps to determine the acceptability of drinking water. The GWQI of the collected groundwater samples from different tubewells nearby waste disposal site was computed using the following Equation 1.

$$
G W Q I=\sum S I_{i}=\sum\left(W_{i} \times q_{i}\right)=\sum\left[\left(\frac{w_{i}}{\sum_{n}^{i=1} w_{i}}\right) \times\left(\frac{C_{i}}{S_{i}} \times 100\right)\right]
$$

Where $C_{i}$ is the concentration of each metal element, $S_{i}$ is the limit values, $w_{i}$ is the assigned weightage, $q_{i}$ is water quality rating, $\mathrm{W}_{\mathrm{i}}$ is the relative weight, $\mathrm{SI}_{\mathrm{i}}$ is the sub-index of $\mathrm{i}^{\text {th }}$ metal element. In this study, weight factors and limit values proposed by (Nabizadeh et al., 2013) and (Vasanthavigar et al., 2010) were considered for evaluating GWQI and provided in Table 1.

Table 1: Parameters, weight factors and limit values considered for the evaluation of GWQI

\begin{tabular}{lcccr}
\hline Parameter & Units & $\begin{array}{c}\text { Weight } \\
\text { factor }\left(\mathrm{w}_{\mathrm{i}}\right)\end{array}$ & $\begin{array}{c}\text { Relative weight } \\
\left(\mathrm{W}_{\mathrm{i}}\right)\end{array}$ & $\begin{array}{r}\text { Limit value } \\
\left(\mathrm{s}_{\mathrm{i}}\right), \mathrm{BIS}\end{array}$ \\
\hline $\mathrm{Fe}$ & $\mathrm{mg} / 1$ & 4 & 0.10 & 0.300 \\
$\mathrm{Mn}$ & $\mathrm{mg} / 1$ & 4 & 0.10 & 0.3 \\
$\mathrm{Cr}(+6)$ & $\mathrm{mg} / 1$ & 4 & 0.10 & 0.05 \\
$\mathrm{Cu}$ & $\mathrm{mg} / 1$ & 2 & 0.05 & 1.5 \\
$\mathrm{~Pb}$ & $\mathrm{mg} / 1$ & 4 & 0.10 & 0.01 \\
$\mathrm{Zn}$ & $\mathrm{mg} / 1$ & 3 & 0.07 & 5 \\
$\mathrm{Ni}$ & $\mathrm{mg} / 1$ & 3 & 0.07 & 0.1 \\
$\mathrm{Cd}$ & $\mathrm{mg} / 1$ & 4 & 0.10 & 0.005 \\
$\mathrm{Na}$ & $\mathrm{mg} / 1$ & 4 & 0.10 & 200 \\
$\mathrm{~K}$ & $\mathrm{mg} / 1$ & 2 & 0.05 & 12 \\
$\mathrm{Ca}$ & $\mathrm{mg} / 1$ & 2 & 0.05 & 200 \\
$\mathrm{As}$ & $\mathrm{mg} / 1$ & 4 & 0.1 & 0.01 \\
$\mathrm{Mg}$ & $\mathrm{mg} / 1$ & 2 & 0.05 & 100 \\
& $\sum w_{i}=$ & 42 & $\sum w_{i}=1.00$ & \\
\hline
\end{tabular}

\subsubsection{Degree of Contamination}

The degree of contamination $\left(\mathrm{C}_{\mathrm{d}}\right)$ of groundwater was computed from the following Equation (2) (Backman et al., 1998).

$$
\mathbf{C}_{\mathbf{d}}=\sum_{\mathbf{i}=\mathbf{1}}^{\mathbf{n}} \mathbf{C}_{\mathbf{f i}}
$$

Where, $\quad C f_{i}=\left(\frac{\mathrm{C}_{\mathrm{ai}}}{\mathrm{C}_{\mathrm{ni}}}\right)-1$ 
Where, $\mathrm{Cf}_{\mathrm{i}}$ is the contamination factor, $\mathrm{C}_{\mathrm{ai}}$ and $\mathrm{C}_{\mathrm{ni}}$ are the analytical value and upper permissible concentration for the ith component respectively, and $\mathrm{n}$ is indicated for the normative value. Here, $\mathrm{C}_{\mathrm{ni}}$ was taken as maximum permissible concentration.

\subsubsection{Heavy Metal Evaluation Index}

Heavy metal evaluation index (HEI) is a method of evaluating water quality parameter contaminated with metal element and interpret a thorough investigation of the level of contamination in groundwater (Prasad and Jaiprakas, 1999). In this study, HEI was calculated using the following Equation (3).

$$
\mathrm{HEI}=\sum_{i=1}^{n} \frac{H_{c}}{H_{\text {mac }}}
$$

Where, $H_{c}$ and $H_{m a c}$ are monitored and maximum admissible value, respectively.

\subsubsection{Metal Element Contamination Index}

Heavy metal contamination index (HPI) is a rating method that qualify water quality with respect to metal elements by assigning unit weightage $\left(\mathrm{W}_{\mathrm{i}}\right)$. The unit weightage $\left(\mathrm{W}_{\mathrm{i}}\right)$ is defined inversely proportional to the standard value $\left(\mathrm{S}_{\mathrm{i}}\right)$ (Mendiguchía et al., 1996). In this study, HPI was computed using the following Equation (4).

$$
\mathrm{HPI}=\frac{\sum_{i=1}^{n} W_{i} Q_{i}}{\sum_{i=1}^{n} W_{i}}
$$

Where, $Q_{i}$ is the sub-index of the $i$ th parameter and $W_{i}$ is unit weight of the $i$ th parameter and $n$ is the number of parameters. In addition, the sub-index $\left(Q_{i}\right)$ was computed by using the following Equation (5).

$$
\mathbf{Q}_{i}=\sum_{i=1}^{n} \frac{\left\{M_{i}(-) I_{i}\right\}}{\left(S_{i}-I_{i}\right)}
$$

Where, $M_{i}, I_{i}$, and $S_{i}$ denote for the 'monitored value', 'ideal value' and 'standard values' of the ith parameter respectively. The negative sign (-) denotes for numerical difference of the two values, ignoring the algebraic sign. Moreover, the unit weightage $W_{\mathrm{i}}$ was computed using the following Equation (6).

$$
W_{i}=\frac{K}{s_{i}}
$$

Where $\mathrm{K}$ is proportional constant.

In this study, the concentration limits i.e., standard value $\left(\mathrm{S}_{\mathrm{i}}\right)$ and ideal value $\left(\mathrm{I}_{\mathrm{i}}\right)$ for each metal element in water were taken from BIS (2012).

\subsection{Multivariate Statistical Analysis}

In this study, principal component analysis (PCA), cluster analysis (CA) and Pearson's correlation were performed using XLSTAT software. Pearson correlation was carried out to demonstrate the correlation coefficient matrix of the ground water quality data in which coefficients of correlation data was calculated using the following Equation (7).

$$
r=\frac{\sum(x y)-\left(\sum x\right)\left(\sum y\right)}{\sqrt{\left[n\left(\sum x^{2}\right)-\left(\sum x\right)^{2}\right]\left[n\left(\sum y^{2}\right)-\left(\sum y\right)^{2}\right]}}
$$

\subsection{Geo-statistical Modelling}

For geostatistical modeling, ordinary kriging (OK) was performed using ArcGIS as an optimal interpolation based on regression against observed values of surrounding data points, weighted according to spatial covariance values (Bohling, 2005). The spatial variation can be illustrated by the following Equation (8) (Delhomme, 1978).

$$
\hat{z}\left(X_{o}\right)=\sum_{i=1}^{n} \lambda_{i} \mathbf{Z}\left(x_{i}\right)
$$

Where $\hat{z}$ is the Estimated value of an attribute at the point of interest $x_{0}, z$ is the observed value at the sample point $\mathrm{x}_{i}, \mathrm{n}$ is the number of sampled points, $\lambda_{\mathrm{i}}$ is the weight assigned to the sampled point.

\section{RESULTS AND DISCUSSION}

The results of groundwater quality, various contamination indices, correlation matrix and spatial distribution of metal elements in groundwater are presented and hence discussed in the following articles. 


\subsection{General Characteristics of Groundwater Quality}

The descriptive statistics in terms of maximum, minimum, mean, standard deviation (SD) and variance of the concentration of metal element in groundwater from tubewells nearby disposal site are provided in Table 2 and Table 3 for rainy and dry season, respectively. The values of SD indicate how much the parameter deviates from mean value. In this study, maximum SD was found for Ca (39.36 for rainy season and 64.43 for dry season) denoted that the concentration of Ca was spread widely from the mean value of it. The metal element of $\mathrm{Cd}$ has the lowest SD ( 0.0016 for rainy season and 0.0017 for dry season) indicated that it was closely related to the mean value. The variance is the squared numerical value of SD of the randomly selected parameter. In this study, maximum and minimum variance follow SD of parameters, for both rainy and dry season, respectively. SD and variance of metal element concentration in dry season was found higher than that of rainy season as the concentration of metal element in groundwater considerably increases from rainy to dry season.

Table 2: Descriptive statistics of physiochemical parameters of metal element in groundwater for rainy season

\begin{tabular}{crrrrrrrrr}
\hline Parameter & Maximum & Minimum & Mean & $\begin{array}{r}\text { Std. } \\
\text { Deviation }\end{array}$ & Variance & $\begin{array}{r}\text { WHO } \\
(2011)\end{array}$ & $\begin{array}{r}\text { BMAC } \\
(1997)\end{array}$ & $\mathrm{S}_{\mathrm{i}}$ & \multicolumn{1}{c}{$\mathrm{Ii}$} \\
\hline $\mathrm{Fe}$ & 0.55 & 0.0134 & 0.11 & 0.156 & 0.0245 & 0.3 & $.3-1$ & 0.3 & 1 \\
$\mathrm{Mn}$ & 1.76542 & 0.026 & 0.368 & 0.475 & 0.2258 & 0.1 & 0.1 & 0.3 & 0.1 \\
$\mathrm{Cr}(+6)$ & 0.08 & 0.003 & 0.031 & 0.020 & 0.00043 & 0.05 & $\mathrm{DNF}$ & 0.05 & 0.01 \\
$\mathrm{Cu}$ & 0.72 & 0.34 & 0.489 & 0.119 & 0.014 & $\mathrm{DNF}$ & $\mathrm{DNF}$ & 1.5 & 0.05 \\
$\mathrm{~Pb}$ & 0.03 & 0.002 & 0.018 & 0.0069 & .00005 & 0.01 & 0.05 & 0.01 & 0.05 \\
$\mathrm{Zn}$ & 1.06666 & 0.029 & 0.327 & 0.3139 & 0.0985 & $\mathrm{DNF}$ & 5 & 5 & 3 \\
$\mathrm{Ni}$ & 0.073 & 0.033 & 0.054 & 0.0118 & 0.0001 & 0.07 & 0.1 & 0.1 & 0.02 \\
$\mathrm{Cd}$ & 0.00653 & 0 & 0.003 & 0.0016 & 0 & 0.003 & $\mathrm{DNF}$ & 0.01 & 0.01 \\
$\mathrm{Na}$ & 120 & 8 & 38.66 & 34.76 & 1208.5 & $\mathrm{DNF}$ & $\mathrm{DNF}$ & 200 & 150 \\
$\mathrm{~K}$ & 30.83 & 11 & 15.28 & 5 & 25 & $\mathrm{DNF}$ & $\mathrm{DNF}$ & 12 & 10 \\
$\mathrm{Ca}$ & 130 & 16 & 48.71 & 39.3568 & 1548.9 & $\mathrm{DNF}$ & $\mathrm{DNF}$ & 200 & 75 \\
$\mathrm{As}$ & 0.038 & 0.002 & 0.016 & 0.0123 & 0.0001 & 0.01 & 0.05 & 0.01 & 0.05 \\
$\mathrm{Mg}$ & 84 & 43 & 56.96 & 9.557 & 91.352 & 0.3 & $\mathrm{DNF}$ & 100 & 30 \\
\hline
\end{tabular}

Table 3: Descriptive statistics of physiochemical parameters of metal elements in groundwater for dry season

\begin{tabular}{crrrrrrrrr}
\hline Parameter & Maximum & Minimum & Mean & $\begin{array}{r}\text { Std. } \\
\text { Deviation }\end{array}$ & Variance & $\begin{array}{r}\text { WHO } \\
(2011)\end{array}$ & $\begin{array}{r}\text { BMAC } \\
(1997)\end{array}$ & Si & Ii \\
\hline $\mathrm{Fe}$ & 2.3 & 1.165 & 1.779 & 0.3698 & 0.1367 & 0.3 & $.3-1$ & 0.30 & 1 \\
$\mathrm{Mn}$ & 0.319 & 0.016 & 0.113 & 0.0833 & 0.007 & 0.1 & 0.1 & 0.3 & 0.1 \\
$\mathrm{Cr}(+6)$ & 0.045 & 0.02 & 0.030 & 0.0085 & .00007 & 0.05 & $\mathrm{DNF}$ & 0.05 & 0.01 \\
$\mathrm{Cu}$ & 0.72 & 0.13 & 0.440 & 0.178 & 0.0318 & $\mathrm{DNF}$ & $\mathrm{DNF}$ & 1.5 & 0.05 \\
$\mathrm{~Pb}$ & 0.05755 & 0.02 & 0.039 & 0.0103 & 0.0001 & 0.01 & 0.05 & 0.01 & 0.05 \\
$\mathrm{Zn}$ & 0.666 & 0.052 & 0.313 & 0.200 & 0.0400 & $\mathrm{DNF}$ & 5 & 5 & 3 \\
$\mathrm{Ni}$ & 0.089 & 0.043 & 0.065 & 0.0133 & 0.0001 & 0.07 & 0.1 & 0.1 & 0.02 \\
$\mathrm{Cd}$ & 0.00653 & 0 & 0.004 & 0.0017 & .00003 & 0.003 & $\mathrm{DNF}$ & 0.01 & 0.003 \\
$\mathrm{Na}$ & 43 & 8 & 18.65 & 9.246 & 85.50 & $\mathrm{DNF}$ & $\mathrm{DNF}$ & 200 & 150 \\
$\mathrm{~K}$ & 24 & 5.14 & 15.10 & 5.9739 & 35.68 & $\mathrm{DNF}$ & $\mathrm{DNF}$ & 12 & 10 \\
$\mathrm{Ca}$ & 258 & 19 & 78.83 & 64.427 & 4150.8 & $\mathrm{DNF}$ & $\mathrm{DNF}$ & 200 & 75 \\
$\mathrm{As}$ & 0.005 & 0.002 & 0.003 & 0.00084 & 0 & 0.01 & 0.05 & 0.01 & 0.05 \\
$\mathrm{Mg}$ & 116 & 52.2 & 63.54 & 16.7951 & 282.07 & 0.3 & $\mathrm{DNF}$ & 100 & 30 \\
\hline
\end{tabular}

\subsection{Contamination Condition in Rainy and Dry Season based on Water Quality Indices}

The contamination indices like GWQI, $\mathrm{C}_{\mathrm{d}}$, HEI and HPI are used for rating the suitability of groundwater for drinking purpose (Abbasi and Abbasi, 2012). Figure 2 represents the fluctuation of these four computed contamination indices in rainy and dry season through a combined manner. The GWQI value ranges from 51.07 to 109.20 with a mean of 82.89 for rainy season (Figure $2 \mathrm{a}$ ). The critical value of GWQI is marked by 100 beyond which if the GWQI of any water sample crosses, then those water samples will be considered as highly contaminated by metal element (Sinha et al., 2004). Result indicates that only $20 \%$ of tubewells yield water having GWQI more than 100 in rainy season. In dry season, $100 \%$ of water from tubewells possess GWQI more than 100 indicating higher contamination of groundwater in dry season (Figure 2a). In addition, $\mathrm{C}_{\mathrm{d}}$ of groundwater discharged by all tubewells in rainy season remains below the critical value of 3 (Al-Nakib et al., 1987) indicating 
low degree of groundwater contamination in rainy season, while, in dry season $53.33 \%$ tubewells possess $C_{d}$ value higher than 3 indicates higher degree of contamination of groundwater (Figure 2b). Moreover, HEI of any tubewell does not exceed the critical value of 20 (Edet and Offiong, 2002) either in rainy or dry season. The HEI ranges from 12.29 to 18.06 with a mean value of 15.4 for dry season represents medium groundwater contamination in compared to rainy season governing less HEI values in all tubewells (Figure 2c). Comparison of HPI in both rainy and dry season reveals that in rainy season, only $13 \%$ water from tubewells having HPI value more than its critical value of 100 (Prasad and Bose, 2001) whereas 27\% of water from tubewells having HPI values exceeded 100 in dry season (Figure 2d). This obvious manner of exceeding critical value interprets high level of groundwater contamination more in dry season than that of rainy season.

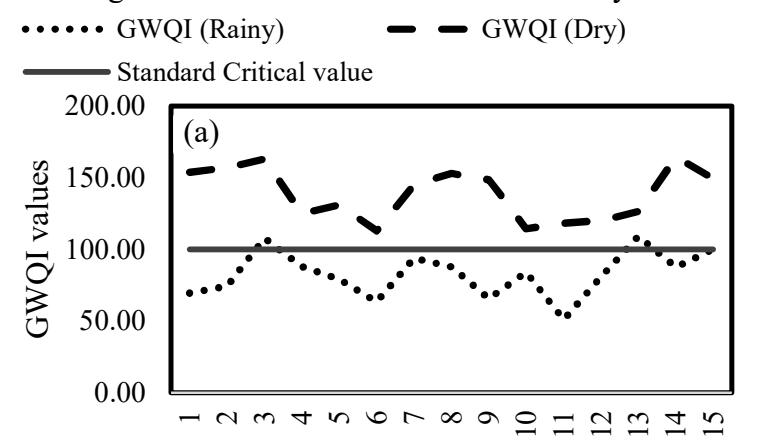

Groundwater sampling points

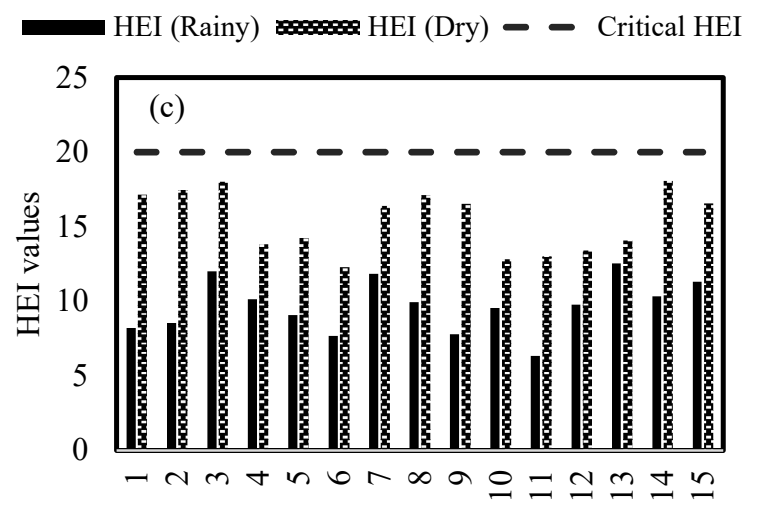

Groundwater sampling points
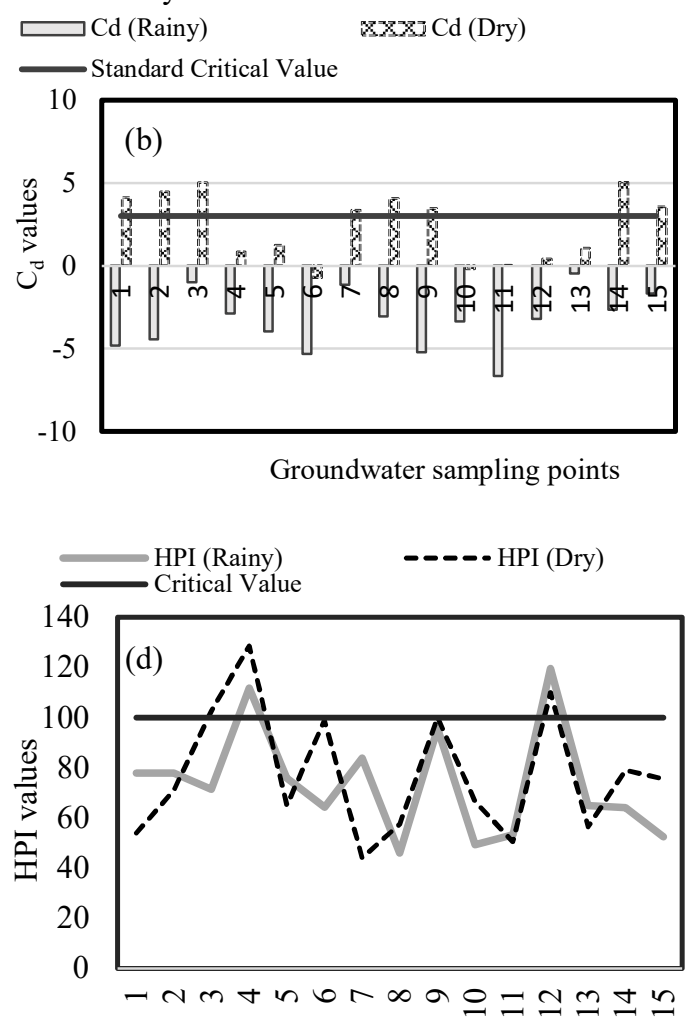

Groundwater sampling points

Figure 2: Contamination condition of groundwater based on (a) GWQI (b) $C_{d}(c)$ HEI and (d) HPI for rainy and dry season

The variation of the results of various containation indices in relatioon to the inceasing groundwater sampling distances is shown in Figure 3. Result reveals concentration of metal element in groundwater decreases with the increasing of sampling distance with respect to the central point of waste disposal site which implied to the decresaing of the values of contamination indices (Figure 3). The tubewells located at a considerable distance from waste disposal site possess less metal element diluted in water. In dry season, the values of contamination indices reduced significantly with the increase of sampling distances, because the disposed contaminants don't find any medium to spread over the area. The nearest groundwater samples i.e. GW1, GW2, etc. from tubewells yield more contaminated with high magnitude of contaminants specified by high values of GWQI, $\mathrm{C}_{\mathrm{d}}$, HEI and HPI for both the dry and rainy seasons [Figures 3(a-d)]. In rainy season, contaminantion indices were found to be less in compared to dry season, therefore contaminants find shallow water soaked in soil to spread over the area. This results an increase of metal element concentration in groundwater even if the tubewells was located in far point from the selected waste disposal site.

The the selected tubewells were then marked based on the level of contamination indices (GWQI, C $\mathrm{d}$, HEI and HPI) and the results of various indices are provided in Table 4. The various indices have different classification of contamination and then the selected tubewells which exceeds their standard limit were maked based on this reference. According to the assessment of GWQI, groundwater from four (26.77\%) nearest tubewells i.e. GW2, GW3, GW4 and GW5 of disposal site were more contaminated than that of other tubewells. It can be marked that water from these four tubewells were very poor condition. However, $73.33 \%$ of water from other tubewells (GW1, GW6, etc.) were poor condion. In addition, the results of $\mathrm{C}_{\mathrm{d}}$ indicates that groundwater from three $(20 \%)$ nearest tubewellsi.e. GW3, GW4 and GW5 were medium as well as $80 \%$ of tubewells were lowly contaminated. The 
results of HEI reveals groundwater from three (20\%) nearest tubewellsi.e. GW2, GW5 and GW6 of disposal site were highly as well as $80 \%$ of tubewellswere low to medium contaminated. However, the results of HPI indicates groundwater from most of the tubewells were medium to highly contaminated.

- GWQI (Rainy) \ GWQI (Dry) $\rightarrow$ Critical value
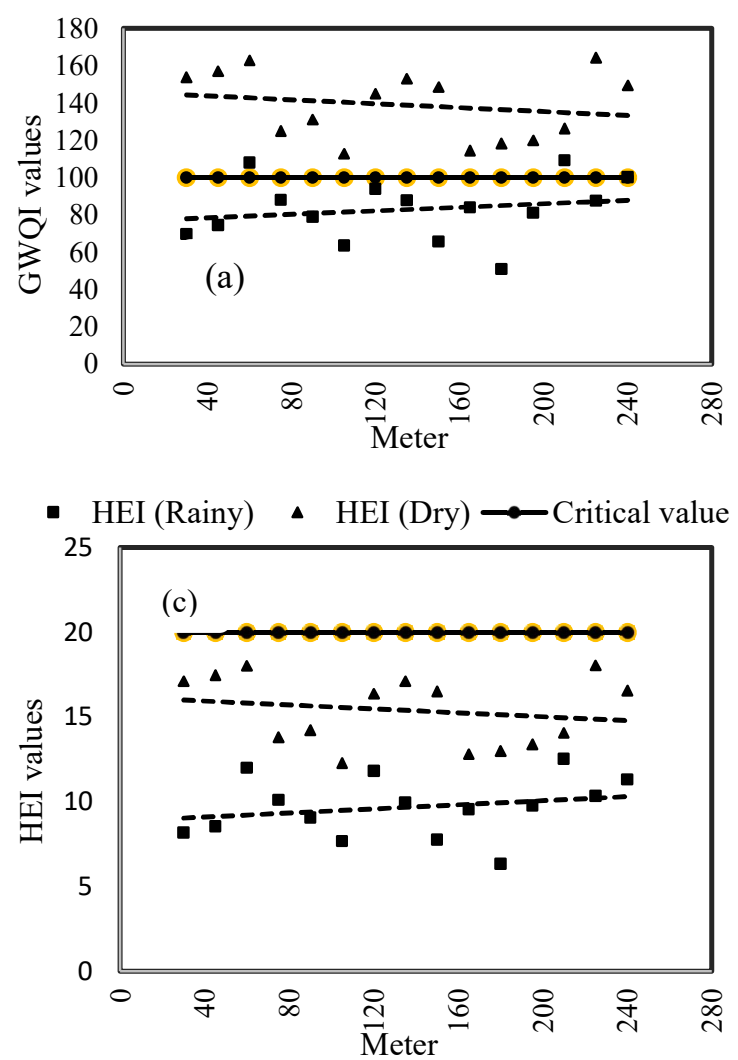

- Cd (Rainy) $\quad$ Cd (Dry) $\rightarrow$ Critical value
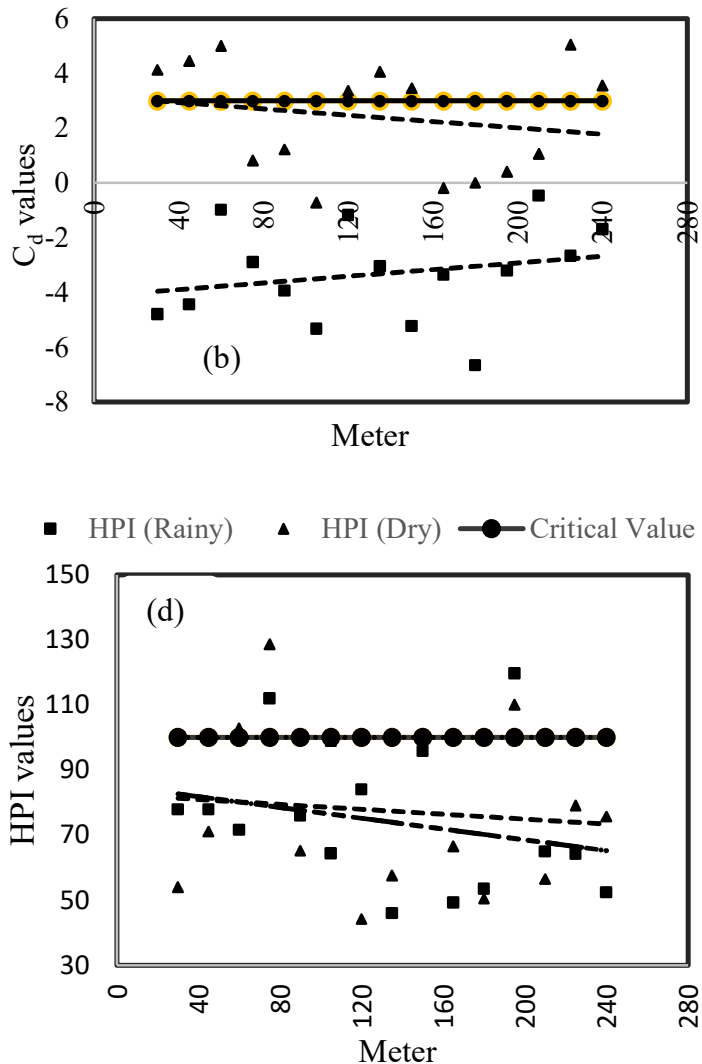

Figure 3: Variation of (a) GWQI) $\mathrm{C}_{d}$ (c) HEI and (d) HPI with respect to water sampling distances (m) from the central point of disposal site for rainy and dry season

\subsection{Contamination Sources and Factors affecting Ground Water Quality}

Multivariate statistical techniques e.g. principle component analysis (PCA), cluster analysis (CA) and Pearson's correlation analysis are commonly used in the environmental engineering studies to understand the sources of pollutants (Mendiguchía et al., 2004). Aanthropogenic/human activities and natural sources are one of the root cause of metal element contamination which has caused widespread and variable the hazardous possibilities of environmental and health effect (Tahir et al., 2007). Moreover, some previous investigations indicated first principal component (PC1) or factor (F1) and second component (PC2) or factor (F2) refers to the contamination of pollutants due to anthropogenic or human activities and natural parent materials, respectively (Tahir et al., 2007; Lu et al., 2012). Anthropogenic sources dominant due to waste disposal, whereas natural activities involved in groundwater chemical alteration. Waste disposal may be attributed the main sources of this groundwater hydrochemical evolution in the study area. The graphical representation of observation and factors is shown in Figure Figure 4. Result reveals that shows that GW5 and GW11 were contaminated by antropogenic sources, while GW6, GW7 and GW12 were contaminated from natural sources (Figure 4a). The water sampling points i.e. GW1, GW2 and GW8 were contaminated by more or less from both sources as their points were significantly far from the factors of F1 and F2 (Figure 4a). From the relationship of variables and factors it can be seen that the present of As in groundwater from anthropogenic sources, while and $\mathrm{Na}, \mathrm{Ca}$ and $\mathrm{Mg}$ from natural sources (Figure 4b). In addition, $\mathrm{Cu}, \mathrm{K}$ and $\mathrm{Cr}$ in groundwater were strongly inter-related based on the sources of contamination as they rely closely to each other. 


\subsection{Spatial Similarity and Sampling Sites Grouping}

In this study, the cluster analysis (CA) was performed to establish the dendrogram of source-based similarities among disposal site and the factor points shown in Figure 5. This dendrogram (Figure 5) denotes the similarities in sources with respect to experimented parameters in a sample cluster (Bodrud-Doza et al., 2016).

The fifteen sampling locations categorized into three clusters; cluster 1 includes five sampling ponits which were GW1, GW2 and GW3 as well as GW8 and GW9 indicating groundwater of these tubewells were contaminated from anthropogenic sources. Moreover, six sampling points fall into cluster 2 category and they were GW4 and GW5, GW10 and GW11 as well as GW14 and GW15 indicates these groundwater were contaminated from natural sources. Cluster 3 have 4 sampling points like GW6 and GW7 as well as GW12 and GW13 indicates these groundwater were contaminated from both the anthropogenic and natural sources. Cluster categories express the similarity of contamination sources among the sampling locations. Main sources of contamination were probably from agricultural fertilizer, domestic sewage drainage, leaching of parent materials, agricultural runoff and so on.

Table 4: Classification of groundwater quality of the study area based on modified categories of quality indices value

\begin{tabular}{|c|c|c|c|c|c|}
\hline Indices & Category & $\begin{array}{c}\text { Degree of } \\
\text { contamination } / \mathrm{Wa} \\
\text { ter Class }\end{array}$ & $\begin{array}{l}\text { Number } \\
\text { of } \\
\text { locations }\end{array}$ & $\begin{array}{c}\% \text { of } \\
\text { Sample }\end{array}$ & Sample ID \\
\hline \multirow[t]{5}{*}{ GWQI } & $<50$ & Excellent water & 0 & 0 & NIL \\
\hline & $50 \sim 100$ & Good water & 0 & 0 & NIL \\
\hline & $100.1 \sim 200$ & Poor water & 11 & 73.33 & $\begin{array}{l}\text { GW1, GW6, GW7, GW8, GW9, GW10, } \\
\text { GW11, GW12, GW13, GW14, GW15 }\end{array}$ \\
\hline & $200.1 \sim 300$ & Very poor water & 4 & 26.67 & GW2, GW3, GW4, GW5 \\
\hline & $>300$ & $\begin{array}{l}\text { Not suitable for } \\
\text { drinking }\end{array}$ & 0 & 0 & NIL \\
\hline \multirow[t]{3}{*}{$\mathrm{C}_{\mathrm{d}}$} & $<10$ & Low & 12 & 80 & $\begin{array}{l}\text { GW1, GW2, GW6, GW7, GW8, GW9, } \\
\text { GW10, GW11, GW12, GW13, GW14, } \\
\text { GW15 }\end{array}$ \\
\hline & $10 \sim 20$ & Medium & 3 & 20 & GW3, GW4, GW5 \\
\hline & $>20$ & High & 0 & 0 & NIL \\
\hline \multirow[t]{3}{*}{ HEI } & $<10$ & Low & 11 & 73.33 & $\begin{array}{l}\text { GW1, GW3, GW4, GW7, GW8, GW9, } \\
\text { GW10, GW12, GW13, GW14, GW15 }\end{array}$ \\
\hline & $10 \sim 20$ & Medium & 1 & 6.67 & GW11 \\
\hline & $>20$ & High & 3 & 20 & GW2, GW5, GW6 \\
\hline \multirow[t]{3}{*}{ HPI } & $<45$ & Low & 0 & 0 & NIL \\
\hline & $45 \sim 90$ & Medium & 1 & 6.67 & GW6 \\
\hline & $>90$ & High & 14 & 93.33 & $\begin{array}{l}\text { GW1, GW2, GW3, GW4, GW5, GW7, } \\
\text { GW8, GW9, GW10, GW11, GW12, } \\
\text { GW13, GW14, GW15 }\end{array}$ \\
\hline
\end{tabular}

Observations (axes F1 and F2: $51.45 \%$ )

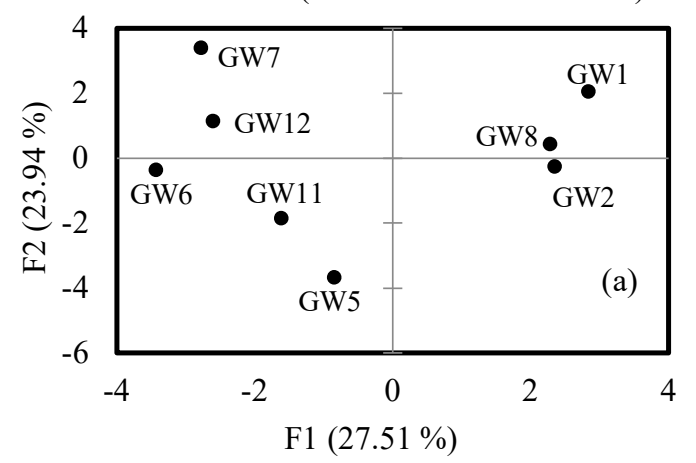

- active observations

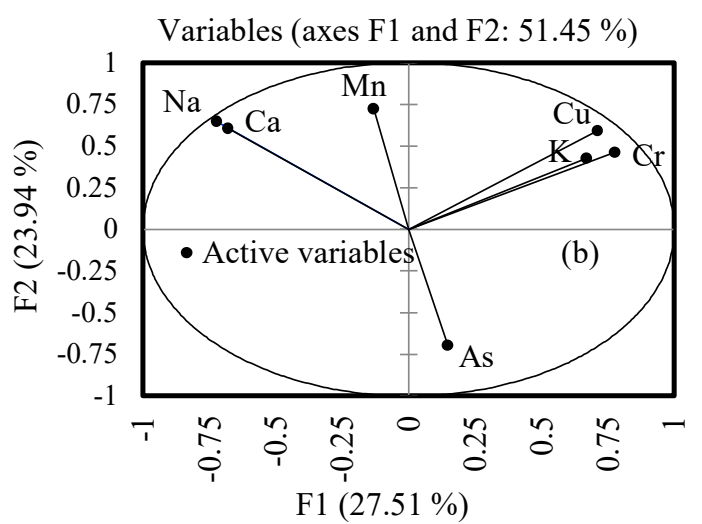

Figure 4: PCA Analysis for (a) active observation and (b) active variables 


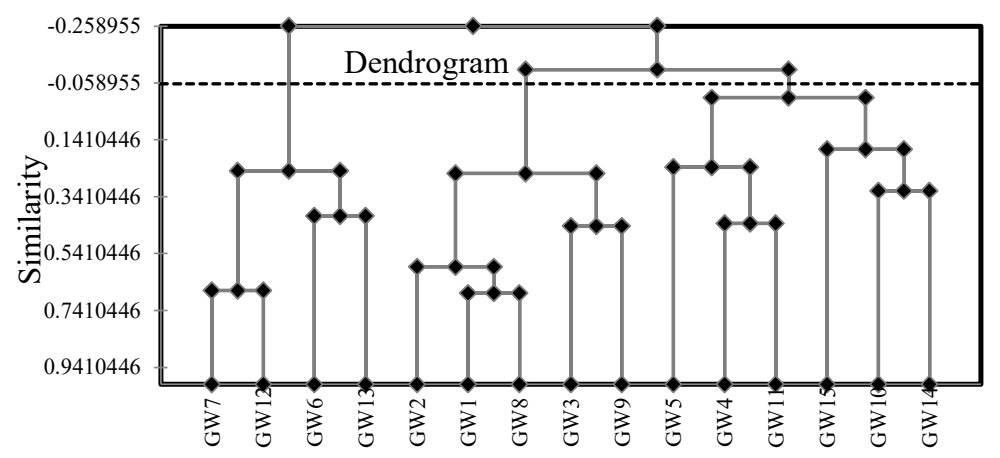

Figure 5: Dendrogram of similarity of parameters and groundwater sampling locations
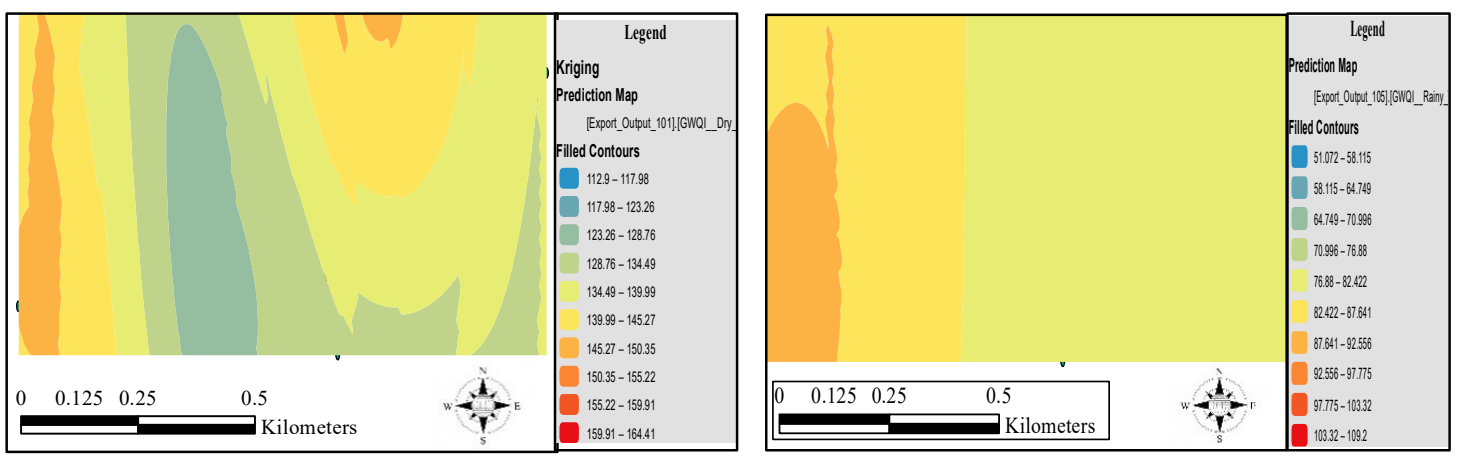

Figure 6: Spatial variation of GWQI for (a) dry season and (b) rainy season
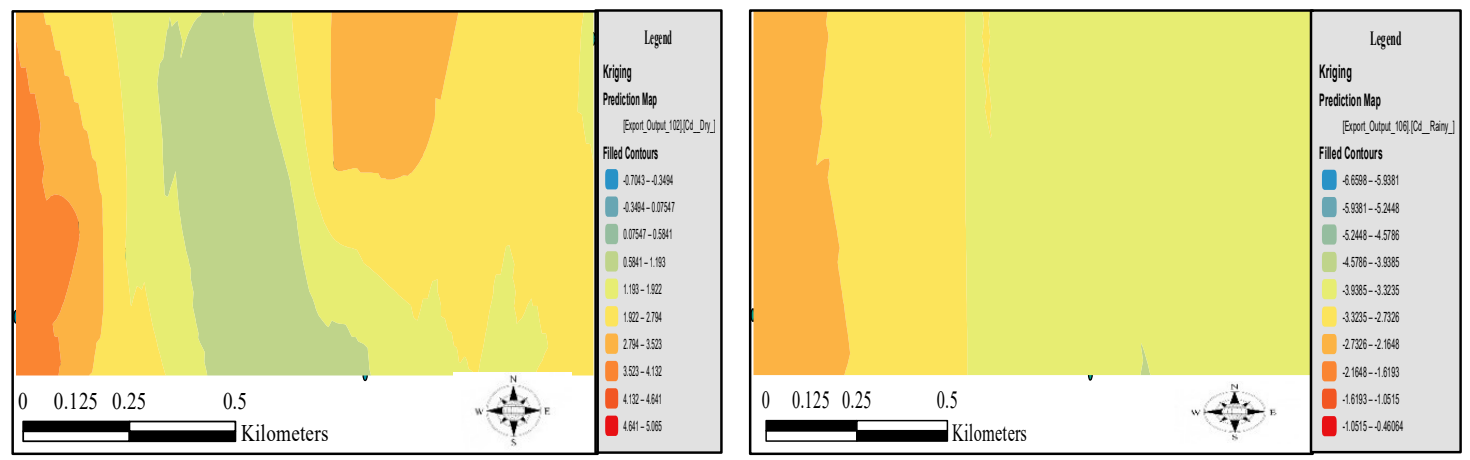

Figure 7: Spatial variation of $\mathrm{C}_{\mathrm{d}}$ for (a) dry season and (b) rainy season
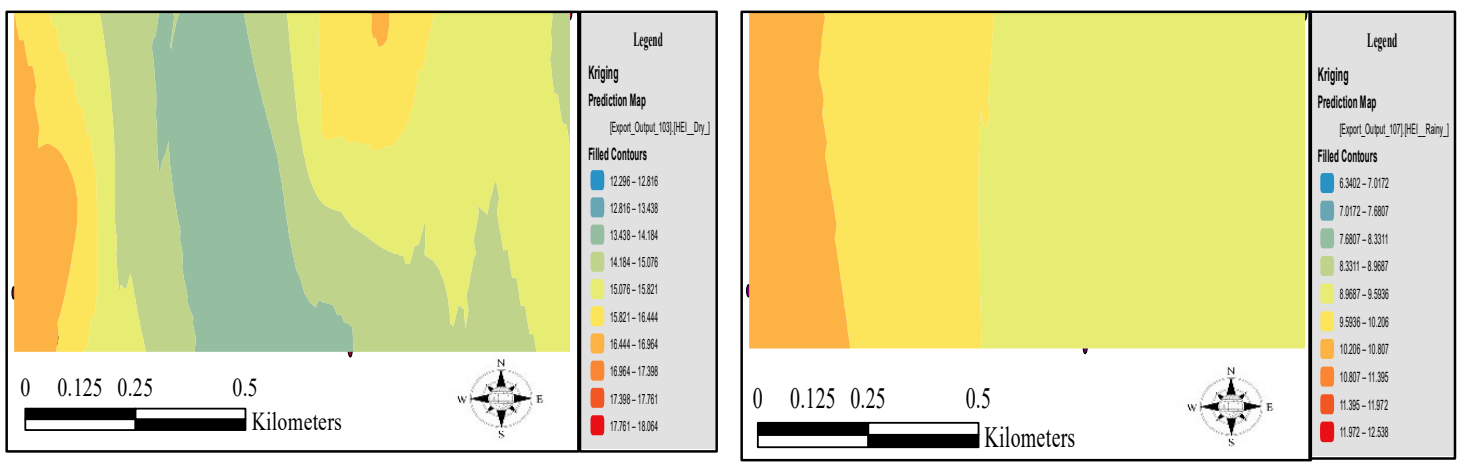

Figure 8: Spatial variation of HEI for (a) dry season and (b) rainy season

\subsection{Spatial Distribution of Contamination Indices}

The spatial distribution of contamination indices interms of GWQI, $\mathrm{C}_{\mathrm{d}}$, HEI and HPI for dry and rainy season is shown in Figures (6-9), respectively. The western part of the dispposal site shows comparatively higher values of GWQI (orange color) than that of eastern part (yellow color) which denotes very poor water and poor water, for 
western and eastern part of the disposal site, respectively (Figure 6). Moreover, most of the area of the selected disposal site consists yellow color with poor water. On the other hand, northern part of the dispposal site shows better quality of water than the southern part (Figure 6). In addition, water quality of tubewells in rainy season (Figure 6b) showed comparatively better than that of dry season (Figure 6a). The spatial distribution of $\mathrm{C}_{\mathrm{d}}$ reveals that the water of tubewells of eastern part was comparatively better than western part (Figure 7). The result of $C_{d}$ reveals that water quality of tubewells in rainy season (Figure 7b) showed comparatively better than that of dry season (Figure 7a). This poor quality of water could be the reason for leaching of ions as well as discharge of wastes or agricultural impacts too to the nearest tubewells (Sahu and Sikdar, 2008). Although the distribution of HPI and HEI shows a complex distribution pattern (Figures 8-9), the distribution of them shows more or less similar pattern. For both distribution, southern part of the area shows very poor water quality than the other sides (Figures 8-9). Anthropogenic/human activities sources may be responsible for this high values of HEI and HPI of tubewells. The spatial distribution maps of all indices confidently indicates more groundwater contamination in dry season than that of rainy season by contour style color variation of various degree of groundwater contamination indices.
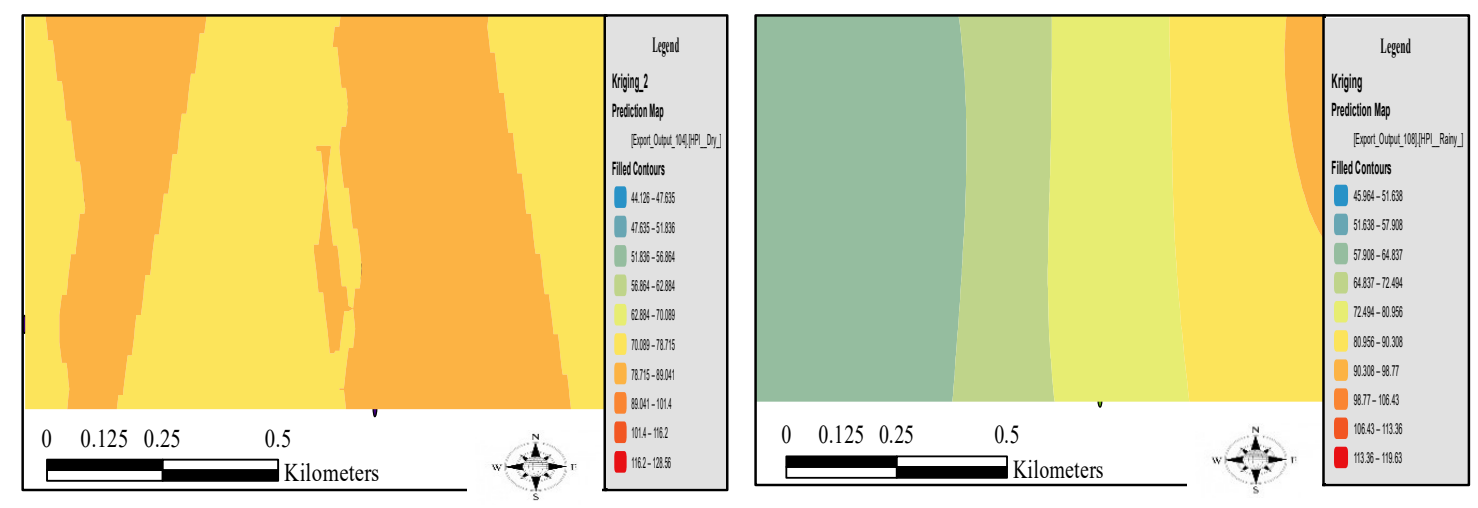

Figure 9: Spatial variation of HPI for (a) dry season and (b) rainy season

Table 5: Pearson's correlation matrix of metal elements in groundwater for rainy season

\begin{tabular}{|c|c|c|c|c|c|c|c|c|c|c|c|c|c|}
\hline & $\mathrm{Fe}$ & $\mathrm{Mn}$ & $\mathrm{Cr}(+6)$ & $\mathrm{Cu}$ & $\mathrm{Pb}$ & $\mathrm{Zn}$ & $\mathrm{Ni}$ & $\mathrm{Cd}$ & $\mathrm{Na}$ & $\mathrm{K}$ & $\mathrm{Ca}$ & As & $\mathrm{Mg}$ \\
\hline $\mathrm{Fe}$ & 1 & & & & & & & & & & & & \\
\hline $\mathrm{Mn}$ & -0.13 & 1 & & & & & & & & & & & \\
\hline $\mathrm{Cr}(+6)$ & 0.14 & -0.28 & 1 & & & & & & & & & & \\
\hline $\mathrm{Cu}$ & -0.20 & 0.55 & 0.20 & 1 & & & & & & & & & \\
\hline $\mathrm{Pb}$ & 0.21 & -0.55 & 0.61 & -0.4 & 1 & & & & & & & & \\
\hline $\mathrm{Zn}$ & -0.35 & -0.07 & 0.07 & -0.2 & 0.33 & 1 & & & & & & & \\
\hline $\mathrm{Ni}$ & -0.17 & -0.21 & -0.66 & -0.6 & -0.1 & 0.02 & 1 & & & & & & \\
\hline $\mathrm{Cd}$ & -0.12 & -0.21 & -0.13 & -0.3 & 0.09 & -0.01 & 0.20 & 1 & & & & & \\
\hline $\mathrm{Na}$ & -0.16 & 0.68 & -0.61 & 0.64 & -0.8 & -0.20 & -0.1 & -0.17 & 1 & & & & \\
\hline $\mathrm{K}$ & -0.22 & 0.46 & -0.36 & 0.56 & -0.2 & 0.01 & 0.02 & 0.00 & 0.73 & 1 & & & \\
\hline $\mathrm{Ca}$ & -0.18 & 0.67 & -0.66 & 0.59 & -0.8 & -0.22 & 0.01 & -0.15 & 0.99 & 0.65 & 1 & & \\
\hline As & -0.12 & -0.48 & -0.09 & -0.6 & 0.45 & 0.57 & 0.43 & 0.34 & -0.4 & -0.1 & -0.4 & 1 & \\
\hline $\mathrm{Mg}$ & -0.15 & 0.17 & -0.10 & 0.33 & 0.08 & 0.00 & 0.14 & -0.02 & 0.32 & 0.71 & 0.22 & 0.09 & 1 \\
\hline
\end{tabular}

\subsection{Pearson's Correlation Matrix}

Pearson's correlation can be used to measure the interrelationship and coherence pattern among of groundwater quality parameters i.e. metal elements. The study of correlation reduces the range of uncertainty associated with decision making (Rogers and Nicewander, 1988). The correlation analysis is a preliminary descriptive technique to estimate the degree of association among the variables involved. The purpose of the correlation analysis is to measure the intensity of association between two variables. Such association is likely to lead to reasoning about causal relationship between the variables. In the study, the correlation matrix showed inter-parameter relationships agreed with the results obtained from XLSTAT analysis with a 95\% confidence level.

The Pearson's correlation of metal elements in groundwater for both rainy and dry season is depicted in Table 5 and Table 6, respectively. The most significant correlation in rainy and dry season was observed for $\mathrm{Na}$ and $\mathrm{Ca}$ having correlation coeffcient -0.16 and -0.18 in rainy season (Table 5) and -0.58 and -0.53 in dry season (Table 6). However, the concentrations of Fe showed very weak correlations with $\mathrm{Cr}$ having correlation coeffcient 0.14 
in rainy and -0.19 in dry season. This indicated that Fe was from different sources than $\mathrm{Cr}$ (Yao et al., 2013). Based on the results of Pearson's correlations matrix during both seasons, it was observed the high positively correlations between $\mathrm{Na}$ and $\mathrm{Ca}(0.938), \mathrm{Cr}$ and $\mathrm{Cu}(0.831), \mathrm{Ca}$ and $\mathrm{Mg}(0.714), \mathrm{Cu}$ and $\mathrm{K}(0.675), \mathrm{Pb}$ and $\mathrm{K}(0.632)$ as well as $\mathrm{Mn}$ and $\mathrm{Na}(0.534)$ were observed (Table 5).

Table 6: Pearson's correlation matrix of metal elements in groundwater for dry season

\begin{tabular}{|c|c|c|c|c|c|c|c|c|c|c|c|c|c|}
\hline & $\mathrm{Fe}$ & $\mathrm{Mn}$ & $\mathrm{Cr}(+6)$ & $\mathrm{Cu}$ & $\mathrm{Pb}$ & $\mathrm{Zn}$ & $\mathrm{Ni}$ & $\mathrm{Cd}$ & $\mathrm{Na}$ & $\mathrm{K}$ & $\mathrm{Ca}$ & As & $\mathrm{Mg}$ \\
\hline $\mathrm{Fe}$ & 1 & & & & & & & & & & & & \\
\hline $\mathrm{Mn}$ & 0.15 & 1 & & & & & & & & & & & \\
\hline $\mathrm{Cr}(+6)$ & -0.19 & 0.35 & 1 & & & & & & & & & & \\
\hline $\mathrm{Cu}$ & 0.48 & 0.72 & 0.48 & 1 & & & & & & & & & \\
\hline $\mathrm{Pb}$ & -0.28 & 0.40 & 0.96 & 0.37 & 1 & & & & & & & & \\
\hline $\mathrm{Zn}$ & 0.34 & 0.11 & 0.19 & 0.44 & 0.09 & 1 & & & & & & & \\
\hline $\mathrm{Ni}$ & -0.03 & -0.64 & 0.12 & -0.2 & 0.06 & 0.21 & 1 & & & & & & \\
\hline $\mathrm{Cd}$ & -0.10 & 0.14 & 0.27 & 0.19 & 0.12 & 0.28 & -0.1 & 1 & & & & & \\
\hline $\mathrm{Na}$ & -0.58 & -0.41 & 0.23 & -0.7 & 0.29 & -0.4 & 0.30 & -0.1 & 1 & & & & \\
\hline K & 0.48 & 0.66 & 0.44 & 0.98 & 0.30 & 0.44 & -0.3 & 0.31 & -0.7 & 1 & & & \\
\hline $\mathrm{Ca}$ & -0.53 & -0.22 & 0.37 & -0.5 & 0.47 & -0.4 & 0.14 & -0.3 & 0.94 & -0.6 & 1 & & \\
\hline As & -0.35 & -0.50 & -0.21 & -0.7 & -0.1 & -0.7 & 0.17 & -0.4 & 0.54 & -0.7 & 0.55 & 1 & \\
\hline $\mathrm{Mg}$ & -0.33 & -0.30 & 0.24 & -0.4 & 0.30 & -0.4 & 0.42 & -0.4 & 0.78 & -0.5 & 0.81 & 0.58 & 1 \\
\hline
\end{tabular}

\section{CONCLUSION}

Result of GWQI reveals $26.67 \%$ of tubewells belong to very poor water, while, $73.33 \%$ of poor water quality of the study area. The results of $\mathrm{C}_{\mathrm{d}}$ and HEI reveals $20 \%$ of groundwater from tubewells were medium to highly as well as $80 \%$ were low to medium contaminated. Results of HPI indicates about most of the tubewells were medium to highly contaminated. The results of contamination indices were found to be comparatively higher for dry season than that of rainy season. Furthermore, results of PCA indicates that the contamination of As was from anthropogenic activities, while, $\mathrm{Na}, \mathrm{Ca}$ and $\mathrm{Mg}$ from natural sources. Pearson's correlation indicates that most of the metal elements were in highly positive correlations with each other. The spatial distribution of various indices reveals that the contamination of groundwater was found comparatively higher for nearest tubewells of the selected disposal site as well as decreases in relation to the increasing of water sampling distances. Therefore, this study of groundwater quality will help city planners and decision makers to adopt right measures to enhance the quality of groundwater in the south-western region of bangladesh.

\section{REFERENCES}

Abbasi, T., and Abbasi S. A., 2012. Approaches to WQI Formulation, Water Quality Indices, https://doi.org/ 10.1016/B978-0-444-54304-2.00002-6, 9-24.

Adipah, S., and Kwame O. N., 2019. A novel introduction of municipal solid waste management, Journal of Environmental Science and Public Health, DOI: 10.26502/jesph.96120055, 3 (2), 147-147.

Al-Nakib, S. M., Ritha N. M., and Nouri A. H., 1987. Water quality index applied to the classification and zoning of Al-Jaysh canal, Baghdad - Iraq AU - Al-Ani, Mohammed Y. Journal of Environmental Science and Health, Part A: Environmental Science and Engineering, https://doi.org/10.1080/10934528709375351, 22(4), 305-319.

Backman, B., Bodiš D., Lahermo P., Rapant S., and Tarvainen T., 1998. Application of a groundwater contamination index in Finland and Slovakia. Environmental Geology, https://doi.org/10.1007/s0025400 50320, 36(1-2), 55-64.

BBS, 2011. Population and Housing Census, 2011, Bangladesh Bureau of Statistics (BBS), National Report, 4.

BIS, 2012. Indian Standards Drinking Water Specifications IS 10500:2012, (May), 11. Retrieved from http:// cgwb.gov.in/Documents/WQ-standards.pdf

Bodrud-Doza, M., Islam A. R. M. T., Ahmed F., Das S., Saha N., and Rahman M. S., 2016. Characterization of groundwater quality using water evaluation indices, multivariate statistics and geostatistics in central Bangladesh. Water Science, https://doi.org/10.1016/j.wsj.2016.05.001, 30(1),19-40.

Bohling, G., 2005. Kriging. Kansas Geological Survey, (October), https://doi.org/10.2104/ag050010, 1-20.

Delhomme, J. P., 1978. Kriging in the hydrosciences. Advances in Water Resources, https://doi.org/ 10.1016/ 0309-1708(78)90039-8, 1(5) 251-266.

Edet, A. E., and Offiong O. E., 2002. Evaluation of water quality contamination indices for metal element contamination monitoring. A study case from Akpabuyo-Odukpani area, Lower Cross River Basin 
(southeastern Nigeria), Geo Journal, https://doi.org/10.1023/B:GEJO.0000007250.92458.de, 57(4), 295304.

Kanmani, S., and Gandhimathi R., 2012. Assessment of heavy metal contamination in soil due to leachate migration from an open dumping site, Applied Water Science, DOI: 10.1007/s13201-012-0072-z. 3(1), 193 205.

Kibria, G., Hossain M. M., Mallick D., Lau T. C., and Wu R., 2016. Monitoring of metal contamination in waterways across Bangladesh and ecological and public health implications of contamination. Chemosphere, https://doi.org/10.1016/j.chemosphere.2016.08, 121, 165, 1-9.

Lu, A., Wang J., Qin X., Wang K., Ha P., and Zhang S., 2012. Multivariate and geostatistical analyses of the spatial distribution and origin of heavy metals in the agricultural soils in Shunyi, Beijing, China, Sci. of the Total Environ, 425, 66-74.

Mangimbulude, J. C., Breukelen B. M., Krave A. S., Straalen N. M., and Röling W. F. M., 2009. Seasonal dynamics in leachate hydrochemistry and natural attenuation in surface run-off water from a tropical disposal site, Waste Management, doi.org/10.1016/j.wasman.2008.06.020, 29(2), 829-838.

Mendiguchía, C., Moreno C., Galindo-Riaño M. D., and García-Vargas M., 2004. Using chemometric tools to assess anthropogenic effects in river water: A case study: Guadalquivir River (Spain). Analytica Chimica Acta, https://doi.org/10.1016/j.aca.2004.01.058, 515(1), 143-149.

Nabizadeh, R., MaryamV.A., Mahmood A., Kazem N., Amir H. M., and Samira Y., 2013. Development of innovative computer software to facilitate the setup and computation of water quality index. J. Environ. Health Sci. Eng.,http://www.ijehse.com/content/11/1/1, 11(1).

Nirmala, D., and Jagath G., 2013. Leachate Characterization and Surface Groundwater, International Journal of Scientific and Research Publications, 3(11), 1-7.

Pangkaj, K. M., and Rafizul I. M., 2019. Human health risk assessment due to the presence of heavy metals in soil of waste disposal site at Khulna in Bangladesh, International Journal of Engineering Science, 10(1), 112 .

Prasad, B., and Bose J., 2001. Evaluation of the metal element contamination index for surface and spring water near a limestone mining area of the lower Himalayas. Environmental Geology, https://doi.org/10.1007/ s002540100380, 41(1), 183-188.

Prasad, B., and Jaiprakas K. C., 1999. Evaluation of metal elementsin ground water near mining area and development of metal element contamination index, Journal of Environmental Science and Health, Part A, https://doi.org/10.1080/10934529909376825, 34(1): 91-102.

Rogers and Nicewander, 1988. Thirteen Ways to Look at the Correlation Coefficient, The American Statistician, 42(1), 59-66.

Sahu, P., and Sikdar P. K., 2008. Hydrochemical framework of the aquifer in and around East Kolkata Wetlands, West Bengal, India. Environmental Geology, https://doi.org/10.1007/s00254-007-1034-x, 55(4), 823-835.

Shah, J. A., Pandit A. K., and Shah G. M., 2014. Spatial and temporal variations of nitrogen and phosphorus in wular lake leading to eutrophication. Ecologia: DOI:103923/ecologia.2014, 4(2), 44-55.

Shen, X., Chi Y., and Xiong K., 2018. The effect of heavy metal contamination on humans and animals in the vicinity of a zinc smelting facility, PLoS ONE: e0207423. https://doi.org/10.1371/journal.pone.0207423, 14(10)

Sinha, D., and Prasad P., 2019. Health effects inflicted by chronic low-level arsenic contamination in groundwater: A global public health challenge, Journal of Applied Toxicology, doi.org/10.1002/jat.3823, 40(1), 87-131.

Sinha, D.K., Saxena S., and Saxena R., 2004. Water quality index for Ram Ganga river at Mordabad. Poll. Res. 23, 527-531.

Tahir, N. M., Chee P. S., and Maisarah J., 2007. Determination of heavy metals content in soils and indoor dusts from nurseries in dungun, The Malay. J. Analy. Sci., 11, 280-286.

Vasanthavigar, M., Srinivasamoorthy K., Vijayaragavan K., Ganthi R. R., Chidambaram S., Anandhan P., Manivannan R., and Vasudevan S., 2010. Application of water quality index for groundwater quality assessment: Thirumanimuttarsub-basin,Tamilnadu, India. Environ. Monit. Assess, http://dx.doi.org/ 10.1007/s10661-009-1302-1, 171(1-4), 595-609

WHO, 2011. Copper in Drinking-water, America,. https://doi.org/10.1016/j.kjms.2011.05.002, 3(23).

Yao, X., Fu B., Lu Y., Sun F., and Wang H., 2013. Comparison of four spatial interpolation methods for estimating soil moisture in a complex terrain catchment, PLoS ONE : e54660. doi:10.1371/journal.pone. 0054660, $8(1)$.

(C) 2021 the Authors. Journal of Engineering Science published by Faculty of Civil Engineering, Khulna University of Engineering \& Technology. This is an open access article under the terms of the Creative Commons AttributionNonCommercial-NoDerivatives License, which permits use and distribution in any medium, provided the original work is properly cited, the use is non-commercial and no Modifications or adaptations are made. 